\title{
Analysis of Marine Sediments for Paleoenvironmental Studies
}

Frank Lamy \& Gerold Wefer

Fachbereich Geowissenschaften, Universität Bremen, Germany; flamy@uni-bremen.de; gwefer@allgeo.uni-bremen.de

\section{The Human Potential - Access to Research Infrastructures (ARI) Programme}

Under the Human Potential-Access to Research Infrastructures (ARI) Programme of the European Community, access is provided for European visiting scientists to research facilities of the Faculty of Geosciences at the University of Bremen (GeoB), Germany.

The Faculty of Geosciences is a leading institution for paleoenvironmental analyses of marine sediments, a key research field for understanding past global changes and the prediction of future global environments. The infrastructure features a unique set of state-of-theart, high capacity facilities for both initial handling and highly sophisticated analyses (e.g., stable isotope and elemental composition) of marine sediments (Fig. 1).

Through financial support from the EC programme, visiting scientists are offered both extensive technical support, crucial for the suc-

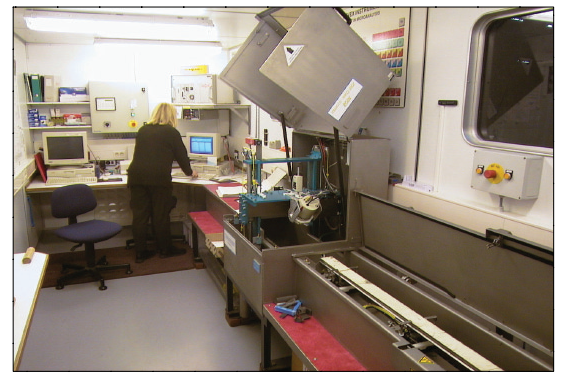

Fig. 1: Example of offered analytical facilities within paleostudies: $X$-ray fluorescence (XRF) core scanner for non-destructive, fast, and closely spaced (as small as $2 \mathrm{~mm}$ ) analyses of major and minor elements in split sediment cores.

cessful application of the highly sophisticated analytical devices, and scientific consultation in the interpretation of the results, especially useful for young visiting scientists. Travel, accommodation, and living expenses for visiting scientists from EU Member and Associated States will be covered for visits of up to 2 months duration.

\section{Research Fields}

Interested European scientists are invited to conduct research projects within the general field of paleoenvironmental reconstruction primarily based on the analysis of marine sediments (though studies on continental archives, such as. lake sediments, are not strictly excluded). In order to guarantee optimum scientific support, potential research should fit within the range of activities at $\mathrm{GeoB}$ which focus on high resolution paleoenvironmental proxy analyses and modelling of:

\section{- Climate and ocean variability on} seasonal to $10^{6}$-year time-scales - Land-ocean interactions

- Marine productivity

\section{Application and Contact}

For more information see:

www.paleostudies.uni-bremen.de or write to:

paleostudies@uni-bremen.de

The next application deadline is September 1, 2002.

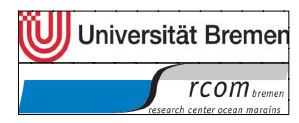

\section{PEP III News}

Following the PEPIII open science conference in August last year, the transect leadership has been reorganized. After extensive consultation, a balanced steering group, both in terms of geographical coverage of the PEPIII transect and scientific expertise, has been formed. We are now happy to report that Thomas Litt has agreed to take overall responsibility, and that he will be advised by a steering group consisting of Nalan Koç, Pepe Carrion, Neil Roberts, Anne-Marie Lézine, Mohammed Umer and Tim Partridge. The group held a first scoping meeting in Bonn in March, 2002 and is now preparing an exciting future program. For more information about PEPIII, contact Thomas Litt (t.litt@uni-bonn.de) or any of the other steering group members or point your browser at http://www.geog.ucl.ac.uk/ecrc/pep3.

PAGES would like to take this opportunity to thank the new steering group for their willingness to serve, and we would also like to thank all of you who put forward nominations and especially those who volunteered their own services.

Finally, the outgoing leadership team, Françoise Gasse, Cathy Stickley and Rick Battarbee would like to thank the PEPIII community for their support and enthusiasm over the last few years culmunating in the enormously successful Aix conference and synthesis book. 